\title{
Serum Magnesium Level Change in Type 2 Diabetic Patients with Cardiovascular Complications
}

\author{
MOHAMMED ELGAZZAR, M.Sc.; ABD ELMOTTALEB TAHA EISSA, M.D.; \\ AMAL SAID ALBENDARY, M.D. and YASSER MOHAMED ABDELRAOUF, M.D.
}

The Department of Internal Medicine, Faculty of Medicine, Tanta University, Egypt

\begin{abstract}
Background: Diabetic macrovascular complications remain the main cause of morbidity and mortality in type 2 diabetes patients. Magnesium is a necessary cofactor for several enzymes that play an important role in glucose metabolism.

Aim of Study: This work was designed to investigate the relation between serum magnesium and diabetic cardiovascular complications.

Patients and Methods: In the present study, 120 patients with type 2 diabetes mellitus were enrolled from Internal Medicine Diabetes and Endocrine Unit Out-patient Clinic, Tanta University Hospitals, Egypt, and 30 individuals as a control within a period of one year. The enrolled individuals were divided into two groups. Group I included 30 healthy non diabetic individuals as control group. Group II included 120 type 2 diabetes patients classified into subgroups;

A- 30 type 2 diabetic patients without any vascular complications.

B- 30 type 2 diabetic patients with ischemic heart disease.

C- 30 type 2 diabetic patients with nephropathy.

D- 30 type 2 diabetic patients with retinopathy.
\end{abstract}

Serum magnesium and other investigations were taken to evaluate the relation between serum magnesium and diabetic macrovascular complications.

Result: Serum magnesium level was significantly low in patients with ischemic heart disease $1.28 \pm 0.36 \mathrm{mg} / \mathrm{dl}$. It was found using recipient characteristic observer curve for magnesium as a predictor of diabetic complications that serum magnesium level of $0.9 \mathrm{mg} / \mathrm{dl}$ was accompanied with $76.4 \%$ sensitivity and $72 \%$ specificity for prediction of complications. While, HbA1C $7.5 \%$ was accompanied with $86.1 \%$ sensitivity and $46.2 \%$ specificity for prediction of macrovascular compilations. Serum magnesium level could be a predictor of occurrence of diabetic complications, but its role in pathogenesis cannot be well stated as our data did not confirm that hypomagnesaemia is an independent risk factor for diabetes complications.

Correspondence to: Dr. Mohammed Elgazzar, The Department of Internal Medicine, Faculty of Medicine, Tanta University, Egypt
Conclusion: From this study, it can be concluded that that serum magnesium level could be a predictor of occurrence of diabetic complications, but its role in pathogenesis cannot be well stated as our data did not confirm that hypomagnesaemia is an independent risk factor for diabetes complications.

Key Words: Serum magnesium - Diabetic patients type 2 Cardiovascular complications.

\section{Introduction}

DIABETIC cardiovascular complications are one of the leading cause of death in diabetic patients. The International Diabetes Federation (IDF) estimated that Egypt is one of the 19 countries and territories of the IDF Middle East and North Africa (MENA) region. The 2017 International Diabetes Federation reported that 425 million persons have diabetes in the world, it is considered that this number will rise to 629 million in 2045. There were 8,222.6 cases of diabetes in Egypt in 2017 [1]. Also, the 2017 International Diabetes Federation report on the global prevalence of diabetes estimated that deaths attributable to diabetes were 4 million deaths, half of them were in people $<60$ years of age [1]. So, it became a demand to search for a parameter that can predict the problem before its occurrence. Insulin and glucose are important regulators of magnesium metabolism, also intracellular magnesium plays a key role in regulating insulin action, insulin-mediated-glucose-uptake and vascular tone. Reduced intracellular magnesium concentrations results in a defective tyrosine-kinase activity, postreceptorial impairment in insulin action and worsening of insulin resistance in diabetic patients [1,2].

\section{Aim of the study:}

This work was designed to investigate the relation between serum magnesium and diabetic cardiovascular complications. 


\section{Patients and Methods}

In the present study, 120 patients with type 2 diabetes mellitus were enrolled from Internal Medicine Diabetes and Endocrine Unit out-patient Clinic, Tanta University Hospitals, Egypt, and 30 healthy individuals as a control within a period of one year from June 2017 to June 2018.

Inclusion criteria: Age $>18$ years, type 2 diabetic patients without complications, type 2 diabetic patients with macrovascular complications (ischemic heart disease) and microvascular complications (retinopathy and nephropathy) were included in the study.

Exclusion criteria: Type 1 diabetes mellitus patients and patients with nephropathy due to any cause other than diabetes mellitus.

Groups' classifications: The enrolled individuals were divided into two groups:

- Group I: It included 30 healthy non diabetic individuals as control group.

- Group II: It included 120 type 2 diabetic patients classified into subgroups:

A- 30 type 2 diabetic patients without any vascular complications.

B- 30 type 2 diabetic patients with ischemic heart disease.

C- 30 type 2 diabetic patients with nephropathy.

D- 30 type 2 diabetic patients with retinopathy.

Methods: All of the studied individuals were subjected to the followings:

1- History of diabetes duration, treatment mode, diabetic retinopathy, ischemic heart disease and diabetic nephropathy were obtained.

2- Complete clinical examination, comprehensive eye examination by ophthalmologist and ECG.

3- Laboratory investigations including fasting and postprandial plasma glucose, serum sodium and potassium levels, serum magnesium level, $\mathrm{HbA} 1 \mathrm{C}$, Albumin creatinine (A/C) ratio in urine, serum creatinine and estimated glomerular filtration rate (e-GFR).

\section{Statistical analysis:}

The collected data were organized, tabulated and statistically analyzed using SPSS version 19 (Statistical Package for Social Studies) created by IBM, Illinois, Chicago, USA. For numerical values the range, mean and SD were calculated. The differences between two mean values were used using student's $t$-test. Differences of mean values between more than two groups were tested by analysis of variance $(F)$ and when found significant, Bonferroni test was used to compare between each two groups. For categorical variable, the number and percentage were calculated and differences between subcategories were tested by chi square test $\left(\mathrm{X}^{2}\right)$. The correlation between two variables was calculated using Pearson's correlation coefficient $(r)$. Binary logistic regression was done to test the effect of both serum magnesium level and glycosylated hemoglobin on the occurrence of diabetic complications. ROC was used to test the predictor cut off value for both serum magnesium and glycosylated hemoglobin predictor for diabetic complications. The level of significant was adopted at $p<0.05$.

\section{Results} (1).

Characters of each group are presented in Table

Baseline characteristics of studied groups showed no significant difference in relation to gender distribution across group I and group II and its subdivisions. While age was significantly higher in diabetic patients with complications in comparison with control group and diabetic patients without complications $(p=0.001)$. Patients with retinopathy had longer duration of diabetes in comparison to other groups ( $p=0.001)$.

The distribution of diabetes complications was shown in Table (1) with some cases of nephropathy, retinopathy and ischemic heart disease were found across different groups of complicated type 2 diabetes.

Among the studied groups; only 28 patients were treated by oral anti-diabetic therapy " 24 of them were in group II-A and 4 of them were in group II-B". The remaining cases were under insulin treatment.

\section{Laboratory data among studied groups:}

As shown in Table (2), the laboratory study revealed that fasting and post prandial plasma glucose in group I was significantly lower than other groups ( $p=0.001)$, also post prandial plasma glucose in group II-A was significantly lower than groups II-C and II-B $(p=0.001)$.

The studied electrolytes revealed that serum sodium in group II-A was significantly lower than in groups I and II-B ( $p=0.002)$, while it was significantly higher in group II-B than in group II-D. Serum potassium in group I was significantly lower than in group II-A. 
Serum magnesium among different groups revealed that it was significantly higher in group I than in group II and its subdivisions, and it was significantly higher in group II-A than in groups II-B and II-D. It was lowest in diabetes with retinopathy group; group II-D ( $p=0.001)$.

Also, the study revealed that serum glycosylated hemoglobin level in group I was significantly lower than in other groups and it was significantly lower in group II-A than in groups II-B and II-D $(p=0.001)$.

Measured serum creatinine and $\mathrm{A} / \mathrm{C}$ ratio among groups revealed that they were significantly higher in group II-C than in other groups ( $p=0.001)$. Similarly, they were significantly higher in group II-B than in groups II-A and II-D, but they were significantly lower in group II-A than in groups II-C, II-B and II-D ( $p=0.001)$. While glomerular filtration rate was significantly lower in group II$\mathrm{C}$ than in other groups, and in group II-B than in groups II-A and II-D ( $p=0.001)$.

Similarly, serum magnesium level was significantly lower in patients with ischemic heart disease compared to patients without ischemic heart disease $(p=0.001)$.

Table (1): Baseline characteristics of patients.

\begin{tabular}{|c|c|c|c|c|c|c|c|c|c|c|c|c|}
\hline \multirow{2}{*}{ Variables } & \multicolumn{2}{|c|}{ Group I } & \multicolumn{2}{|c|}{ Group II-A } & \multicolumn{2}{|c|}{ Group II-B } & \multicolumn{2}{|c|}{ Group II-C } & \multicolumn{2}{|c|}{ Group II-D } & \multirow{2}{*}{$\mathrm{X}_{2}$} & \multirow{2}{*}{$p$} \\
\hline & $\mathrm{n}$ & $\%$ & $\mathrm{n}$ & $\%$ & $\mathrm{n}$ & $\%$ & $\mathrm{n}$ & $\%$ & $\mathrm{n}$ & $\%$ & & \\
\hline \multicolumn{13}{|l|}{ Sex: } \\
\hline Males & 10 & 33.3 & 14 & 46.7 & 17 & 56.7 & 16 & 53.3 & 10 & 33.3 & 5.826 & 0.213 \\
\hline Females & 20 & 66.7 & 16 & 53.3 & 13 & 43.3 & 14 & 46.7 & 20 & 66.7 & & \\
\hline \multicolumn{13}{|l|}{ Age: } \\
\hline Range & \multicolumn{2}{|c|}{$18-58$} & \multicolumn{2}{|c|}{$30-59$} & \multicolumn{2}{|c|}{$38-70$} & \multicolumn{2}{|c|}{$40-71$} & \multicolumn{2}{|c|}{$50-72$} & 50.851 & $0.001 *$ \\
\hline Mean \pm SD & \multicolumn{2}{|c|}{$33.03 \pm 11.30$} & \multicolumn{2}{|c|}{$42.77 \pm 9.36$} & \multicolumn{2}{|c|}{$55.63 \pm 7.73$} & \multicolumn{2}{|c|}{$54.80 \pm 7.25$} & \multicolumn{2}{|c|}{$60.40 \pm 6.46$} & & \\
\hline \multicolumn{13}{|c|}{ Duration of diabetes: } \\
\hline Range & \multirow{2}{*}{\multicolumn{2}{|c|}{-}} & \multicolumn{2}{|c|}{$1-10$} & \multicolumn{2}{|c|}{$2-20$} & \multicolumn{2}{|c|}{$5-20$} & \multicolumn{2}{|c|}{$1-20$} & 27.683 & $0.001 *$ \\
\hline Mean \pm SD & & & \multicolumn{2}{|c|}{$4.97 \pm 2.24$} & \multicolumn{2}{|c|}{$9.97 \pm 4.81$} & 10.4 & \pm 3.99 & & \pm 4.61 & & \\
\hline Family histor & & & & & & & & & & & & \\
\hline Negative & 25 & 83.3 & 18 & 60.0 & 11 & 36.7 & 10 & 33.3 & 16 & 53.3 & 34.75 & $0.001 *$ \\
\hline Positive & 5 & 16.6. & 12 & 40.0 & 19 & 63.3 & 20 & 66.7 & 14 & 46.7 & & \\
\hline Nephropathy: & & & & & & & & & & & & \\
\hline Absent & 30 & 100 & 30 & 100 & 3 & 10.0 & 0 & 0.0 & 11 & 36.7 & 111.3 & $0.001 *$ \\
\hline Present & 0 & 0.0 & 0 & 0.0 & 27 & 90.0 & 30 & 100 & 19 & 63.3 & & \\
\hline Retinopathy: & & & & & & & & & & & & \\
\hline Absent & 30 & 100 & 30 & 100.0 & 27 & 90.0 & 27 & 90.0 & 0 & 0.0 & 120.4 & $0.001 *$ \\
\hline Present & 0 & 0.0 & 0 & 0.0 & 3 & 10.0 & 3 & 10.0 & 30 & 100.0 & & \\
\hline Ischemic hea & & & & & & & & & & & & \\
\hline Absent & 30 & 100.0 & 30 & 100.0 & 0 & 0.0 & 26 & 86.7 & 24 & 80.0 & 107.7 & $0.001 *$ \\
\hline Present & 0 & 0.0 & 0 & 0.0 & 30 & 100.0 & 4 & 13.3 & 6 & 20.0 & & \\
\hline Grade of reno & & & & & & & & & & & & \\
\hline I & 30 & 100.0 & 30 & 100.0 & 3 & 10.0 & 0 & 0.0 & 11 & 36.7 & MCET & $0.001 *$ \\
\hline II & 0 & 0.0 & 0 & 0.0 & 23 & 76.7 & 0 & 0.0 & 10 & 33.3 & & \\
\hline III-a & 0 & 0.0 & 0 & 0.0 & 3 & 10.0 & 6 & 20.0 & 5 & 16.7 & & \\
\hline III-b & 0 & 0.0 & 0 & 0.0 & 1 & 3.3 & 17 & 56.7 & 1 & 3.3 & & \\
\hline IV & 0 & 0.0 & 0 & 0.0 & 0 & 0.0 & 7 & 23.3 & 3 & 10.0 & & \\
\hline
\end{tabular}

*Significant. $\quad$ MCET $=$ Monte carlo exact test. $\quad \mathrm{SD}=$ Standard deviation 
In studied groups; there was significant association between decrease of serum magnesium level and elevated glycosylated hemoglobin level $(p=0.001)$ as presented in Table (4).

Our work revealed highly significant negative correlation between serum magnesium level and $\mathrm{HbA} 1 \mathrm{C}$, fasting and post prandial plasma glucose level and duration of diabetes $(p=0.001)$. Also, there was significant negative correlation between serum magnesium and serum potassium, creatinine, grade of nephropathy and $\mathrm{A} / \mathrm{C}$ ratio $(p=0.003$, $0.001,0.001,0.001$, respectively). While, a positive correlation was found between serum magnesium and serum sodium and glomerular filtration rate $(p=0.003,0.001$, respectively) as shown in Table (5) and Figs. (1-4).

To know if serum magnesium level is independent risk factor for ischemic heart disease, apart from level of $\mathrm{HbA} 1 \mathrm{C}$, regression analysis was done. It showed that the more the elevation in $\mathrm{HbA} 1 \mathrm{C}$ the more the incidence of complications occurred as Exp. B is 7.637 that means elevated 1 unit accompanied with elevated incidence of complications 7.637 time while serum magnesium level showed Exp. B $0.786(<1)$ which means decreasing level of serum magnesium is accompanied with increased level of complications and should be accompanied with elevated $\mathrm{HbA} 1 \mathrm{C}$ to induce this effect (Table 6).

It was found using recipient characteristic observer curve (ROC) for serum magnesium as predictor of diabetic complications that serum magnesium level of $0.9 \mathrm{mg} / \mathrm{dl}$ was accompanied with $76.4 \%$ sensitivity and $72 \%$ specificity for prediction of complications. While HbA1C $7.5 \%$ was accompanied with $86.1 \%$ sensitivity and $46.2 \%$ specificity for prediction of compilations (Fig. 5).

Table (2): Laboratory results among studied groups.

\begin{tabular}{|c|c|c|c|c|c|c|c|}
\hline Variables & Group I & Group II-A & Group II-B & Group II-C & Group II-D & $\mathrm{F}$ & $p$ \\
\hline \multicolumn{8}{|c|}{ Fasting plasma glucose: } \\
\hline Range & $80-98$ & $111 \pm 210$ & $115-318$ & $118-338$ & $120-213$ & \multirow[t]{2}{*}{28.72} & \multirow[t]{2}{*}{$0.001 *$} \\
\hline Mean \pm SD & $91.60 \pm 4.30$ & $153.70 \pm 26.40$ & $180.03 \pm 46.52$ & $180.47 \pm 54.89$ & $163.47 \pm 33.29$ & & \\
\hline \multicolumn{8}{|c|}{ Postprandial plasma } \\
\hline glucose: & & & & & & & \\
\hline Range & $101-118$ & $200-309$ & $203-350$ & $180-420$ & $201-390$ & \multirow[t]{2}{*}{59.422} & \multirow[t]{2}{*}{$0.001 *$} \\
\hline Mean \pm SD & $110.67 \pm 4.54$ & $221.77 \pm 30.08$ & $257.80 \pm 48.83$ & $271.43 \pm 71.48$ & $254.80 \pm 49.27$ & & \\
\hline \multicolumn{8}{|l|}{ Serum sodium: } \\
\hline Range & $135-145$ & $135-145$ & $129-145$ & $128-145$ & $128-145$ & \multirow[t]{2}{*}{4.343} & \multirow[t]{2}{*}{$0.002 *$} \\
\hline Mean \pm SD & $140.23 \pm 2.74$ & $137.23 \pm 3.30$ & $140.40 \pm 3.70$ & $138.47 \pm 5.12$ & $137.53 \pm 4.19$ & & \\
\hline \multicolumn{8}{|c|}{ Serum potassium: } \\
\hline Range & $3.5-5.0$ & $4.0-5.5$ & $3.5-5.5$ & $3.5-6.5$ & $3.5-5.6$ & \multirow[t]{2}{*}{2.732} & \multirow[t]{2}{*}{$0.031 *$} \\
\hline Mean \pm SD & $4.35 \pm 0.59$ & $4.80 \pm 0.52$ & $4.60 \pm 0.54$ & $4.77 \pm 0.60$ & $4.55 \pm 0.75$ & & \\
\hline \multicolumn{8}{|c|}{ Serum magnesium: } \\
\hline Range & $1.5-2.5$ & $1.0-2.3$ & $0.8-2.0$ & $0.7-2.2$ & $0.8-1.9$ & \multirow[t]{2}{*}{22.055} & \multirow[t]{2}{*}{$0.001 *$} \\
\hline Mean \pm SD & $2.00 \pm 0.30$ & $1.61 \pm 0.32$ & $1.32 \pm 0.39$ & $1.36 \pm 0.38$ & $1.29 \pm 0.35$ & & \\
\hline \multicolumn{8}{|c|}{ Serum glycosylated } \\
\hline hemoglobin le & & & & & & & \\
\hline Range & $5-5.5$ & $6.5-11$ & $7-11$ & $7-11$ & $7-11$ & \multirow[t]{2}{*}{62.867} & \multirow[t]{2}{*}{$0.001 *$} \\
\hline Mean \pm SD & $5.07 \pm 0.17$ & $7.97 \pm 0.99$ & $8.88 \pm 1.34$ & $8.63 \pm 1.33$ & $9.05 \pm 1.39$ & & \\
\hline \multicolumn{8}{|c|}{ Serum creatinine: } \\
\hline Range & $0.6-1.0$ & $0.7-1.0$ & $0.7-1.9$ & $1.3-2.9$ & $0.5-2.1$ & \multirow[t]{2}{*}{69.731} & \multirow[t]{2}{*}{$0.001^{*}$} \\
\hline Mean \pm SD & $0.79 \pm 0.11$ & $0.82 \pm 0.09$ & $1.08 \pm 0.20$ & $1.86 \pm 0.35$ & $1.10 \pm 0.47$ & & \\
\hline \multicolumn{8}{|c|}{ Glomerularfiltration } \\
\hline rate: & & & & & & & \\
\hline Range & $90-110$ & $90-107$ & $39-91$ & $18-56$ & $25-136$ & \multirow[t]{2}{*}{67.974} & \multirow[t]{2}{*}{$0.001 *$} \\
\hline Mean \pm SD & $100.74 \pm 11.78$ & $94.95 \pm 4.61$ & $68.84 \pm 12.73$ & $37.19 \pm 9.41$ & $75.20 \pm 31.37$ & & \\
\hline \multicolumn{8}{|l|}{ A/C ratio: } \\
\hline Range & $3-15$ & $5-30$ & $8-90$ & $33-600$ & $5-400$ & \multirow[t]{2}{*}{23.362} & \multirow[t]{2}{*}{$0.001^{*}$} \\
\hline Mean \pm SD & $7.97 \pm 3.79$ & $19.60 \pm 6.76$ & $44.30 \pm 22.36$ & $182.10 \pm 137.61$ & $75.03 \pm 109.04$ & & \\
\hline
\end{tabular}


Table (3): Distribution of studied groups by ischemic heart diseases.

\begin{tabular}{lllll}
\hline & \multicolumn{5}{c}{ Ischemic heart diseases } \\
\cline { 2 - 5 } Groups & \multicolumn{2}{c}{ Negative } & \multicolumn{2}{c}{ Positive } \\
\cline { 2 - 5 } & $\mathrm{n}$ & $\%$ & $\mathrm{n}$ & $\%$ \\
\hline Group I & 30 & 100.0 & 0 & 0.0 \\
Group II-C & 26 & 86.7 & 4 & 13.3 \\
Group II-B & 0 & 0.0 & 30 & 100.0 \\
Group II-A & 30 & 100.0 & 0 & 0.0 \\
Group II-D & 24 & 80.0 & 6 & 20.0 \\
$\mathrm{X}^{2}$ & \multicolumn{5}{c}{107.727} \\
$p$ & \multicolumn{5}{c}{$0.001^{*}$} \\
\hline
\end{tabular}

*Significant.

Table (4): Comparison of serum magnesium level in relation to glycosylated hemoglobin.

\begin{tabular}{llc}
\hline \multirow{2}{*}{$\begin{array}{l}\text { Serum magnesium } \\
\text { level }\end{array}$} & \multicolumn{2}{c}{ Glycosylated hemoglobin } \\
\cline { 2 - 3 } & $\leq 7$ & $>7$ \\
\hline Range & $1-2.5$ & $0.7-2.2$ \\
Mean \pm SD & $1.93 \pm 0.28$ & $1.27 \pm 0.31$ \\
$t$ & 13.364 & \\
$p$ & $0.001^{*}$ & \\
\hline
\end{tabular}

*Significant.

Table (5): Correlation between serum magnesium level and other variables.

\begin{tabular}{lcc}
\hline \multirow{2}{*}{ Variables } & \multicolumn{2}{c}{ Serum magnesium level } \\
\cline { 2 - 3 } & $r$ & $p$ \\
\hline Duration of diabetes & -0.372 & $0.001^{*}$ \\
Serum sodium & 0.243 & $0.003^{*}$ \\
Serum potassium & -0.198 & $0.003^{*}$ \\
Glycosylated hemoglobin & -0.813 & $0.001^{*}$ \\
Fasting plasma glucose & -0.705 & $0.001^{*}$ \\
Postprandial plasma glucose & -0.729 & $0.001^{*}$ \\
Creatinine & -0.387 & $0.001^{*}$ \\
Glomerular filtration rate & 0.458 & $0.001^{*}$ \\
Grade of nephropathy & -0.506 & $0.001^{*}$ \\
A/C ratio & -0.395 & $0.001^{*}$ \\
\hline
\end{tabular}

*Significant .

Table (6): Binary logistic regression for the effect of glycosylated hemoglobin and serum magnesium level on the occurrence of diabetic complications.

\begin{tabular}{llcc}
\hline Variables & Wald & $p$ & Exp. B \\
\hline Glycosylated hemoglobin & 10.441 & $0.001 *$ & 7.637 \\
Serum magnesium level & 0.143 & 0.702 & 0.786 \\
\hline
\end{tabular}

*Significant.

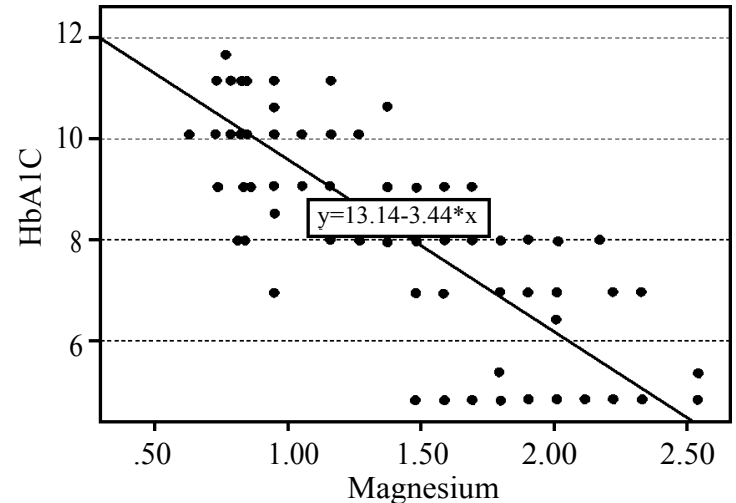

Fig. (1): Correlation between serum magnesium level and glycosylated hemoglobin.

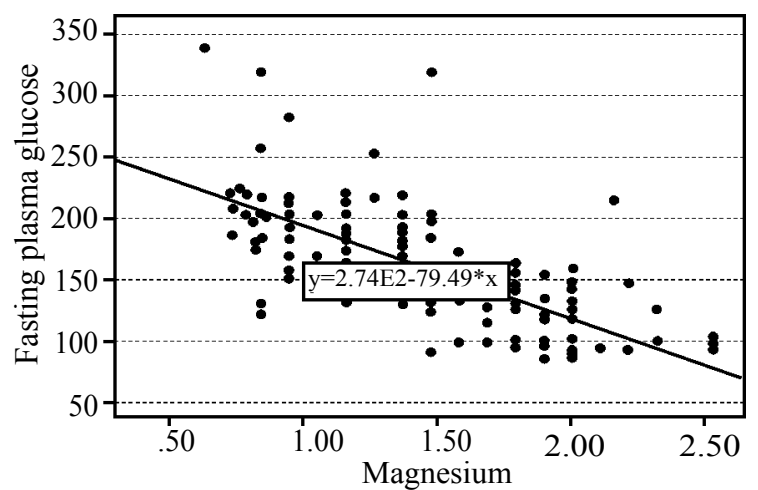

Fig. (2): Correlation between serum magnesium level and fasting plasma glucose

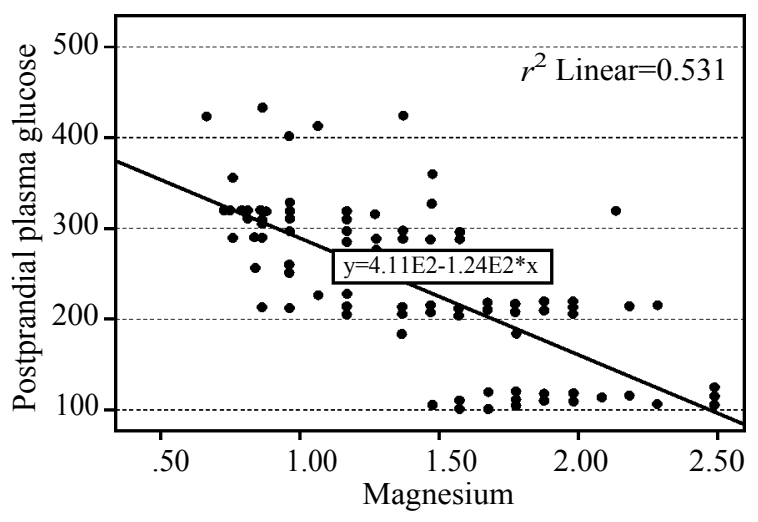

Fig. (3): Correlation between serum magnesium level and postprandial plasma glucose

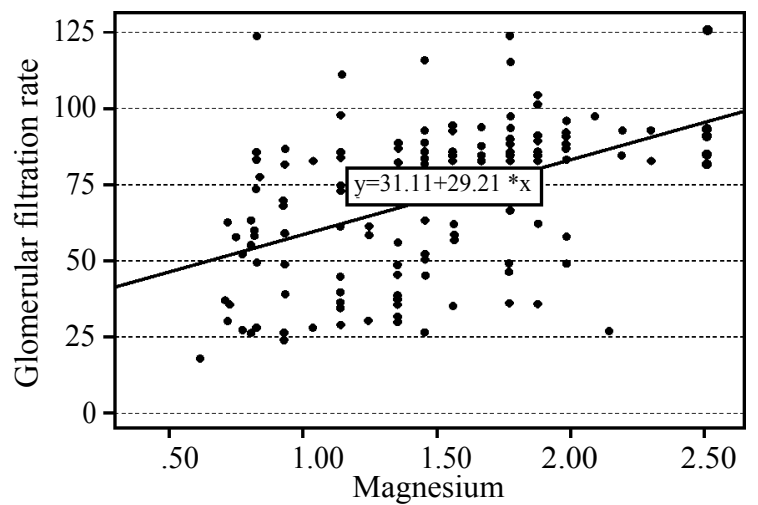

Fig. (4): Correlation between serum magnesium level and glomerular filtration rate. 


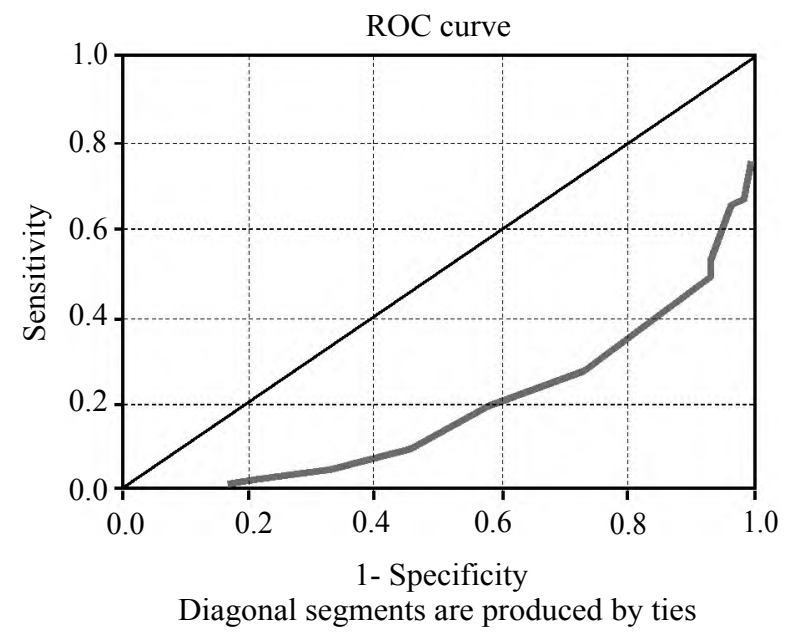

Fig. (5): ROC curve for serum magnesium level as a predictor of overall complications.

\section{Discussion}

Relation between magnesium and diabetes has been studied in many researches [3-6] in different locations, but according to our best knowledge, this relationship was not studied in Egyptian patients.

The higher prevalence of diabetic complications among the elderly in our study could be attributed to the rise of diabetes mellitus prevalence among elderly. Moreover, Paolisso stated that advanced aging is characterized by a number of pathophysiological alterations leading to frailty which is a syndrome of decreased reserve and resistance to stress [7]. Furthermore, Yanase et al reported that the occurrence of frailty depends on deterioration in muscle and nerve function and declining cardiopulmonary reserve [8]. The downward spiral of frailty is activated more quickly in elderly type 2 diabetic patients, and frailty itself is associated with increased expression of inflammatory and coagulation markers that contribute to occurance of the microvascular and macrovascular complications of type 2 diabetes. Thus, there is a positive feedback between the high prevalence of diabetic complications and old age. They added that insulin resistance or insulin depletion may be an important factor in frequent occurance of diabetic complications among the elderly.

The present study revealed that serum magnesium was significantly low in macrovascular complications groups than in diabetics without complications and it was lowest in diabetic retinopathy group. It was found using recipient characteristic observer curve for magnesium as a predictor of diabetic complications that serum magnesium level of $0.9 \mathrm{mg} / \mathrm{dl}$ was accompanied with $76.4 \%$ sensitivity and $72 \%$ specificity for prediction of complications.

Also, Kareem et al., observed a low serum magnesium level in diabetic patients and the level was lowest in patients with diabetic retinopathy [9]. This is also similar to the findings of Saproo $\&$ Singh, who revealed low magnesium levels in diabetic patients and concluded that it can be used as a marker to predict retinopathy [5]. Peters et al., suggested that extracellular and intracellular magnesium deficiency is typical in chronic, stable, mild type 2 diabetes and may be an independent risk factor for the development of the excess cardiovascular complications associated with diabetes

Concerning the hypomagnesaemia in the diabetic groups with macrovascular complications, Baig et al., found similar results [11]. They suggested that hypomagnesaemia may act through inhibition of prostacyclin receptor function producing an imbalance between prostacyclin and thromboxane which has marked atherogenic potential responsible for microvascular complications. Additionally, Pham et al., mentioned that low serum magnesium levels can secondarily induce hypocalcaemia and hypophosphatemia, potentially causing further derangements in neuromuscular and cardiovascular physiology. Hypomagnesaemia has been implicated in various long-term complications of diabetes mellitus, such as hypertension, increased carotid wall thickness, coronary artery disease, dyslipidemia, diabetic retinopathy, neuropathy, iscaemic stroke and foot ulcerations [12]. Also, Kochar \& Shrotriya, found that low serum magnesium may lead to abnormal increased cellular proliferation and increased arterial wall thickness leading to hypertension and ischemic heart disease [13] .

In the present study, HbA1C $7.5 \%$ was accompanied with $86.1 \%$ sensitivity and $46.2 \%$ specificity for prediction of micro and macrovascular compilations. Our finding is in agreement with the use of version 2 of the United Kingdom Prospective Diabetes Study (UKPDS) Outcomes Model. This allowed greater precision of risk including risk of developing a diabetes related ulcer, second myocardial infarction and stroke events with high HbA1C [14]

The Diabetes Control and Complications Trial/Epidemiology of Diabetes Interventions and Complications (DCCT/EDIC), reported that the 
higher $\mathrm{HbA} 1 \mathrm{C}$ is related to diabetic retinopathy and other macrovascular complications [15]. Another study was performed by Miller et al., who targeted progressively lower HbA1C levels. They found that such lower $\mathrm{HbAl} \mathrm{C}$ level has the potential for greater reduction of estimated risk of type 2 diabetic complications, more pronounced in microvascular than macrovascular complications [16] They added that $0.7 \%$ reduction in the HbA1C value might be expected to produce a reduction in the rate of macrovascular events by approximately one sixth. Meanwhile, NedaL et al., stated that each $1 \%$ unit increase in $\mathrm{HbA} 1 \mathrm{C}$ was associated with a 1.26-fold increased risk of cardiovascular disease [17].

Hyperglycaemia leads to formation of succinate and activation of its receptor (GPR91) 31 in renal, cardiac, pulmonary and other tissues. This results in renin release and links the local effects of elevated glucose with the intrarenal and the systemic activation of renin angiotensin aldosterone system. Griffin et al., study stated that there is a positive association between renin and HbA1C [18]. Furthermore, the "legacy effect" or "metabolic memory" from early improvement of glycemic control in both the UKPDS and DCCT/EDIC has been linked to the formation of advanced glycation end products (AGEs) in the tissues of poorly controlled patients that correlate with macrovascular complications [19].

Contrary, Pradhan et al., found that HbA $1 \mathrm{C}$ predicts diabetes and microvascular complications but not macrovascular complications [20]. The Action in Diabetes and Vascular Disease: Preterax and DiamicronMR Controlled Evaluation (ADVANCE) trial, the Veterans Affairs Diabetes Trial (VADT), and the Action to Control Cardiovascular Risk in Diabetes (ACCORD) similarly enrolled high risk patients and concluded that $\mathrm{HbA} 1 \mathrm{C}$ levels $>7 \%$ did not show increased short term cardiovascular risk or mortality and also they did not demonstrate a significant reduction of cardiovascular events in the intensive group compared to the standard group [21-23], but after nearly 10 years of follow-up in VADT and ACCORD studies, fewer major cardiovascular events were found in the intensive group compared to the standard group [24-25] . Furthermore, Zoungas et al., stated that even with control of glucose level, cardiovascular risk and mortality risk will not decrease [26]. Also, Kumamoto reported that in all type 2 diabetic patients, $\mathrm{HbA} 1 \mathrm{C}$ should be maintained $<7.0 \%$ to prevent microangiopathy but not macroangiopathy [27].
Our study indicates that serum magnesium level could be a predictor of occurance of diabetic complications, but its role in pathogenesis of complications cannot be well stated as our data did not confirm that hypomagnesaemia is an independent risk factor for diabetes complications.

The result as a predictor goes with Wahid et al., who stated that hypomagnesaemia is a predictor for diabetic complications especially retinopathy [28]. In addition, Gommers et al., stated that serum magnesium should be a routine part of investigation pool of diabetics [29]. We recommend routine magnesium investigation to diabetic patients.

\section{References}

1- International Diabetes Federation IDF Diabetes Atlas, 8th edn. Brussels, Belgium: International Diabetes Federation.; www.idf.org/diabetesatlas, 2017.

2- BARBAGALLO M. and DOMINGUEZ L.: Magnesium and type 2 diabetes. World J. Diabetes., 6 (10): 11521157, 2015.

3- GOMMERS L., HOENDEROP J., BINDELS R. and JEROEN H.: Hypomagnesemia in Type 2 Diabetes: A Vicious Circle? Diabetes, 65 (1): 3-13.

4- MANIKANDAN S., RAJENDRAN K., SUTHAKARAN P., et al.: Study on serum magnesium levels and glycemic status in newly detected type 2 diabetes patients. Int. J. Adv. Med., 3 (1): 11-14, 2016.

5- SAPROO N. and SINGH R.: Study of serum magnesium levels in diabetes mellitus and its correlation with complications (retinopathy and HbA1C) a cross-sectional study of one year. Int. J. Adv. Med., 4 (1): 263-269, 2017.

6- WAHID A., VERMA G., MEENA C. and PATHAN A.: Study of serum magnesium level in patients with type 2 diabetes mellitus and it's correlation with glycosylated hemoglobin and diabetic complications. Int. J. Adv. Med., 4 (2): 22-28, 2017.

7- PAOLISSO G.: Pathophysiology of diabetes in elderly people. Acta. Biomed., 81 (1): 47-53, 2010.

8- YANASE T., YANAGITA I., MUTA K. and NAWATA H.: Frailty in elderly diabetes patients. Endocr. J., 65 (1): $1-11,2018$.

9- KAREEM I., JAWEED S.A., BARDAPURKAR J.S. and PATIL V.P.: Study of magnesium, glycosylated hemoglobin and lipid profile in diabetic retinopathy. Ind. J. Clin. Biochem., 19 (2): 124-127, 2004.

10- PETERS K.E., CHUBB P., DAVIS W.A. and DAVIS T.M.E.: The Relationship between Hypomagnesemia, Metformin Therapy and Cardiovascular Disease Complicating Type 2 Diabetes: The Fremantle Diabetes Study. Plos One, 8 (9): e74355, 2016.

11- BAIG M.S., SHAMSHUDDIN M., MAHADEVAPPA K.L., ATTAR A.H. and SHAIKH A.K.: Serum magnesium as a marker of diabetic complications. J. Evol. Med. Dent. Sci., 1: 119-233, 2012. 
12- PHAM P.C., PHAM P.A., PHAM S.V., PHAM P.T., PHAM P.M. and PHAM P.T.: Hypomagnesemia: A clinical perspective. Int. J. Nephrol. Renovasc. Dis., 7: 219-230, 2014.

13- KOCHAR A. and SHROTRIYA R.: Serum Magnesium Levels in Type II Diabetes Mellitus and Its Association with the Microvascular Complications. Int. Arch. Bio. Med. Clin. Res., 4 (1): 127-129, 2018.

14- STRATTON I.M., ADLER A.I., NEIL H.A., et al.: UK Prospective Diabetes Study Group. Association of glycaemia with macrovascular and microvascular complications of type 2 diabetes (UKPDS 35): Prospective observational study. BMJ, 321: 405-412, 2000.

15- Nathan D.M. and for the DCCT/EDIC Research Group. The Diabetes Control and Complications Trial/Epidemiology of Diabetes Interventions and Complications study at 30 years: Overview. Diabetes Care, 37: 9-16, 2014

16- MILLER G., ANDERSON S., COSTACOU T., SEKIKAWA A. and ORCHARD T.: Hemoglobin A1 c Level and Cardiovascular Disease Incidence in Persons With Type 1 Diabetes: An Application of Joint Modeling of Longitudinal and Time-to-Event Data in the Pittsburgh Epidemiology of Diabetes Complications Study. Am. J. Epidemiol., 187 (7): 1520-1529, 2018.

17- NEDAL L., ANDREW J., KARTERB H., et al.: Ten-year hemoglobin A1c trajectories and outcomes in type 2 diabetes mellitus: The diabetes \& aging study. J. of Diabet. and its Comp., 31 (1): 94-100, 2017.

18- GRIFFIN T., WALL D., BROWNE G., DENNEDY M. and O'SHEA P.: Associations between glycaemic control and activation of the renin-angiotensin-aldosterone system in participants with type 2 diabetes mellitus and hypertension. Ann of Clinical Bioch., 55 (3): 3 73-3 84, 2018.

19- RIDDLE M.C., GERSTEIN H.C., HOLMAN R.R., et al.: A1C Targets Should Be Personalized to Maximize Benefits While Limiting Risks. Diabetes Care, 41: 1121-1124, 2018.

20- PRADHAN A.D., RIFAI N., BURING J.E. and RIDKER P. M.: Hemoglobin A $1 \mathrm{c}$ predicts diabetes but not cardio- vascular disease in nondiabetic women. Am. J. Med., 120: 720-727, 2007.

21- PATEL A., MACMAHON S., CHALMERS J., et al.: ADVANCE Collaborative Group. Intensive blood glucose control and vascular outcomes in patients with type 2 diabetes. N. Engl. J. Med., 358: 2560-2572, 2008.

22- DUCKWORTHW., ABRAIRA C., MORITZ T., et al.: VADT Investigators. Glucose control and vascular complications in veterans with type 2 diabetes. N. Engl. J. Med., 360: 129-139, 2009.

23- HUANG E., LAITEERAPONG N., JENNIFER Y., PRIYA M., MOFFET H. and ANDREW J.: Rates of complications and mortality in older patients with diabetes mellitus the diabetes and aging study. JAMA Intern. Med., 174 (2): 251-258, 2014.

24- HAYWARD R.A., REAVEN P.D., WIITALA W.L., et al.: Follow-up of glycemic control and cardiovascular outcomes in type 2 diabetes. N. Engl. J. Med., 372 (23): 2197-2206, 2015.

25- Gerstein H.C.: Nine-Year Effects of 3.7 Years of Intensive Glycemic Control on Cardiovascular Outcomes. Diabetes Care, 39 (5): 701-708, 2016.

26- ZOUNGAS S., PATEL A., CHALMERS J., et al.: ADVANCE Collaborative Group. Severe hypoglycemia and risks of vascular events and death. N. Engl. J. Med., 363: 1410-1418, 2010.

27- NAKANISHI S., HIRUKAWA H., SHIMODA M., et al.: Verification of Kumamoto Declaration 2013 and Glycemic Targets for Elderly Patients with Diabetes in Japan for prevention of diabetic complications: A retrospective longitudinal study using outpatient clinical data. J. of Diabetes Inves., 12: 47-53, 2018.

28- WAHID A., VERMA G., MEENA C. and PATHAN A.: Study of serum magnesium level in patients with type 2 diabetes mellitus and it's correlation with glycosylated hemoglobin and diabetic complications. Int. J. Adv. Med., 4 (2): 22-28, 2017.

29- GOMMERS L., HOENDEROP J., BINDELS R. and JEROEN H.: Hypomagnesemia in Type 2 Diabetes: A Vicious Circle? Diabetes, 65 (1): 3-13, 2016. 


\section{تغيرنسبة الماغنسيوم بالمصل فى المرضى المصابين بداء السكرى

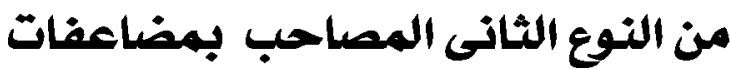 أمراض القلب والأوعية الدموية الدموية}

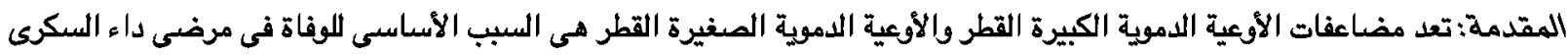

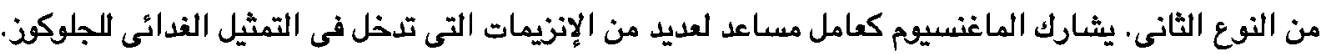

الهدف من العهل: هدفت هذه الدراسة إلى البحث عن العلاقة بين نسبة الماغنسيوم بالمصل ومضاعفات القلب والأوعية الدموية الناتجة عن داء السكرى.

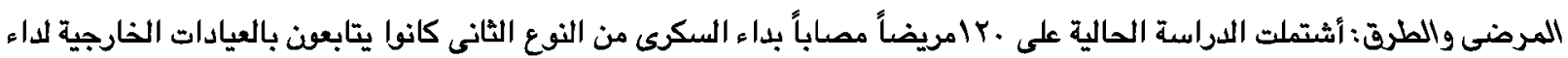

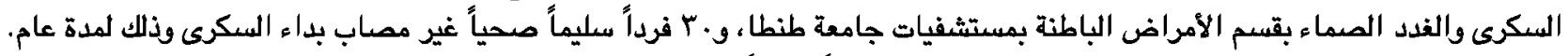

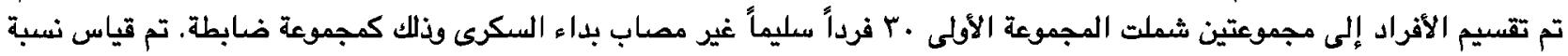

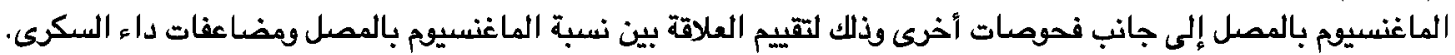

النتائج: بإستخدام منحنى روك لقياس القيمة القطعية لكل من المعايير التنبؤية، تم قياس قدرة الماغنسيوم للتنبؤ بحدوث مضاعفات داء

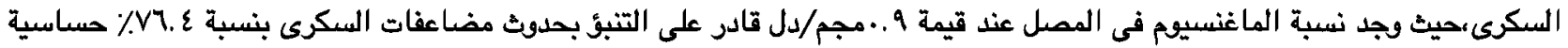

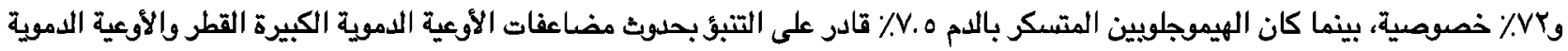

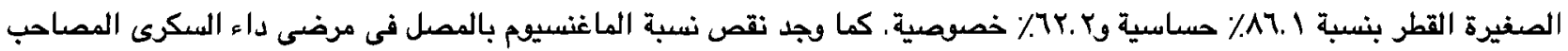

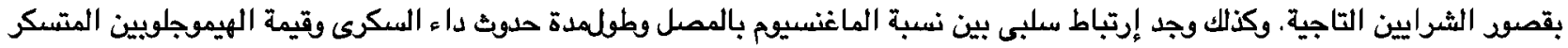

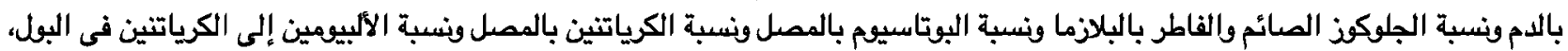

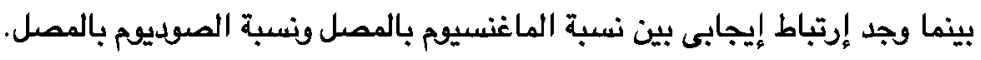

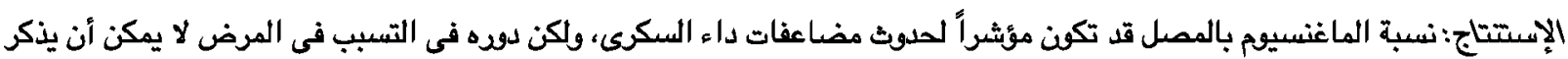

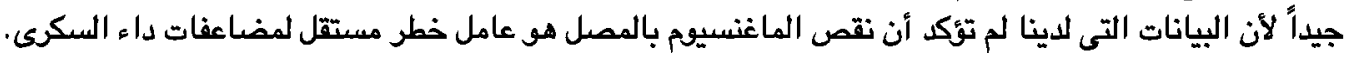

